\title{
DESENVOLVIMENTO DE UMA COLUNA DE FLOTAÇÃO POR AR DISSOLVIDO COM ESTÁGIOS PARA SEPARAÇÃ̃o ÁGUA ÓLEO
}

\author{
K. A. L. dos $\operatorname{SANTOS}^{1}$, M. BENACHOUR ${ }^{1}$, L. A. SARUBBO ${ }^{2,3}$, V. A. dos $\operatorname{SANTOS}^{2,3}$ \\ ${ }^{1}$ Universidade Federal de Pernambuco, Departamento de Engenharia Química \\ ${ }^{2}$ Universidade Católica de Pernambuco, Departamento de Engenharia Química \\ ${ }^{3}$ Centro de Gestão de Tecnologia e Inovação \\ E-mail para contato: kamylla_alexandre@yahoo.com
}

RESUMO - Água residuária oleosa é uma grande fonte de poluição gerada nos estágios de produção, transporte e manutenção de instalações industriais, geralmente para utilização de derivados de petróleo. O descarte ou até mesmo o reúso da água oleosa só é permitido após a remoção do óleo e dos sólidos em suspensão a níveis aceitáveis. Atualmente, o processo de flotação vem atraindo a atenção dos estudiosos devido à sua alta eficiência de separação, o baixo investimento de capital e baixos custos operacionais. Desse modo, no presente trabalho desenvolveu-se um arranjo de bancada, para promover a separação água-óleo utilizando flotação por ar dissolvido (FAD). Para análise preliminar da eficiência de separação do arranjo FAD foram analisados dados experimentais do funcionamento de dois estágios. Foi aplicado um Delineamento Composto Central Rotacional (DCCR), do tipo $2^{2}$, para definição das condições operacionais. A aplicação da metodologia de superfície de resposta deu origem a gráficos tridimensionais que auxiliaram na análise dos dois estágios dispostos em série. Como conclusão das investigações foi proposta uma coluna FAD com estágios, visto que a técnica de colocar esses estágios em série mostrou-se vantajosa na eficiência de remoção de óleo.

\section{INTRODUÇÃO}

Águas residuárias são todas as águas descartadas que resultam de diferentes processos, tais como, industrial, doméstico, infiltração, etc. (Monte; Albuquerque, 2010). Essas águas transportam uma quantidade apreciável de materiais poluentes que, se não forem retirados podem prejudicar a qualidade das águas dos rios, comprometendo todo o ecossistema e as suas posteriores utilizações.

Apesar de serem considerados líquidos imiscíveis, a dificuldade de separar óleo da água depende da proporção entre os dois fluidos e do mecanismo de mistura. Óleo derramado em águas residuárias pode ser separado usando separação gravitacional, enquanto que o óleo disperso em água (rotor de bombas e atrito com as paredes de tubulações) pode ser removido por 
tratamento biológico (Xiao-Bing, 2007). Óleo disperso e emulsionado ocorre em suspensão coloidal, sendo muito difícil de separar por causa do tamanho pequeno das gotas.

Segundo Santander et al. (2011) existem muitas técnicas disponíveis para a separação de emulsões de óleo-água, nomeadas por: filtros, ultra-filtração, micro-filtração, osmose reversa, separação por gravidade, tratamento de lamas ativadas, flotação de ar dissolvido, coluna de flutuação, flotação com gás, eletroflotação, induzido por flotação por ar, biorreator de membrana, adsorção de carbono, coagulação química e eletrocoagulação.

Segundo Fonseca (2010) a flotação surgiu como um eficiente processo de tratamento de efluentes oleosos, pois é uma operação unitária utilizada para a separação de uma fase sólida ou líquido emulsionada em um fase líquida, através da introdução de pequenas bolhas de gás, as quais aderindo á superfície das partículas aumentam seu empuxo, provocando assim, a ascensão das mesmas, em direção a superfície da fase liquida, podendo então ser devidamente coletadas. Essa combinação de técnicas deverá reduzir ao máximo o tempo de recuperação do elemento impactado e, sobretudo, não interferir no estado estacionário que deve reger o funcionamento do sistema afetado.

Com o desenvolvimento do setor industrial, a aplicação do processo de flotação começou a ser difundido em refinarias, indústrias de curtumes, mecânicas, petroquímicas, no tratamento de águas para abastecimento, entre outros (Valentine; Carawan, 1996). Neste contexto, se fez necessário o aperfeiçoamento da técnica inicial ocasionando a criação do processo de flotação por ar dissolvido (FAD). Atualmente, no setor industrial o processo FAD vem sendo bastante usado como pré-tratamento de efluentes industriais com grande concentração de substâncias insolúveis como gorduras, óleos e graxas (Metcalf; Eddy, 2003).

As colunas de flotação têm provado suas importâncias em vários setores industriais, bem como na resolução de problemas ambientais. Entretanto, o funcionamento das colunas tem sido limitado pela forma com que esses equipamentos foram elaborados - por analogia com colunas de borbulhamento, dando origem a regiões de baixa eficiência de separação na parte superior da coluna (Shukla et al., 2010). A partir dessas observações, a proposta deste trabalho é um equipamento em forma de coluna com estágios, utilizando o processo de flotação por ardissolvido, capaz de melhorar a eficiência de separação água - óleo.

\section{Material e Métodos}

\subsection{Arranjo Experimental de Bancada}

O arranjo de bancada deste trabalho compreende de dois estágios, ou duas câmaras de flotação dispostas em série. A entrada do efluente no equipamento é realizada pela primeira câmara câmara, produzindo desde esse ponto dois fluxos de materiais com densidades diferentes. A fase aquosa escoa por gravidade para a segunda câmara. Em cada estágio é admitido um fluxo 
de água saturada por ar para produção de microbolhas, obtido com auxílio da água tratada coletada na saída do arranjo. Um segundo fluxo de material, compreendendo uma espécie de espuma oleosa é obtido por transbordamento em cada estágio.

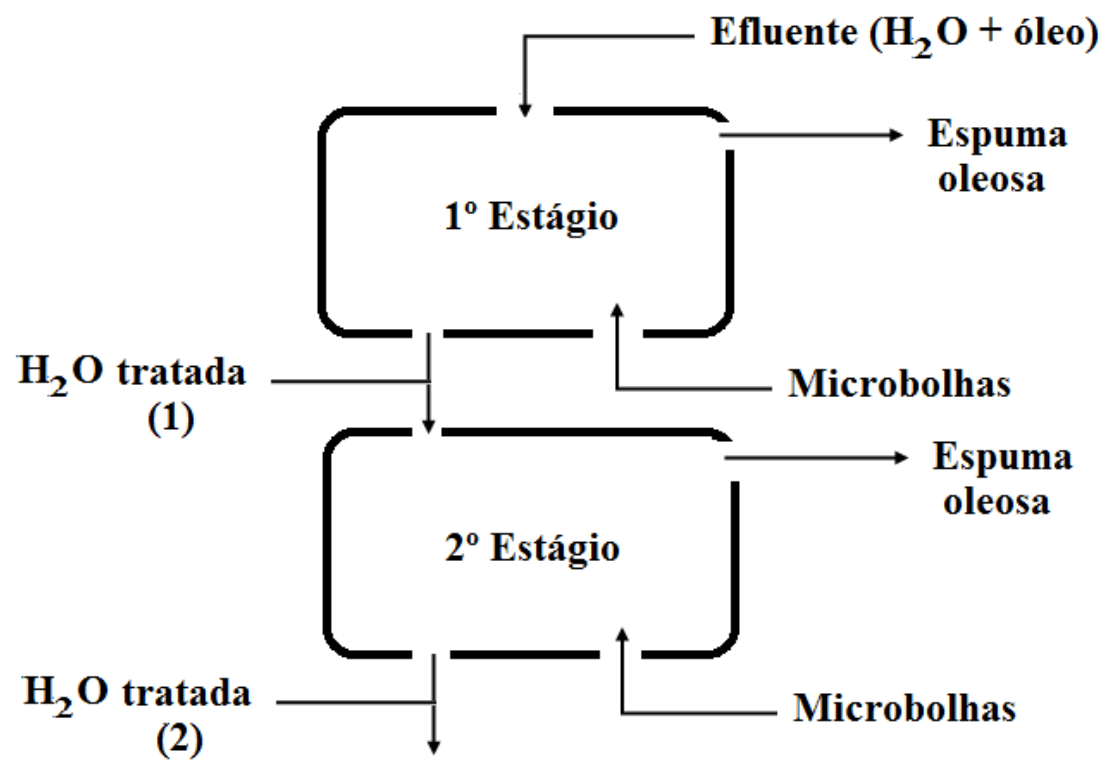

Figura 1 - Esquema do arranjo de bancada FAD

\subsection{Planejamento dos Experimentos}

Para análise preliminar da eficiência de separação do arranjo de bancada FAD foram analisados dados experimentais do funcionamento dos dois estágios. Foi aplicado um Delineamento Composto Central Rotacional (DCCR), do tipo $2^{2}$, para definição das condições operacionais. Como variáveis independentes foram utilizadas a razão entre as vazões ar/água, para produção de microbolhas $\left(\mathrm{X}_{1}\right)$ e, a razão óleo/água de alimentação $\left(\mathrm{X}_{2}\right)$, como visto na Tabela 1. Dessa forma, foram realizados um total de 12 experimentos, constando de 4 pontos fatoriais completos, 4 pontos centrais e 4 pontos axiais. 
Tabela 1 - Valores codificados e normais dos fatores

\begin{tabular}{lcccccc}
\hline & \multicolumn{7}{c}{ Níveis } \\
\hline \multicolumn{1}{c}{ Fator } & Código & $-1,41$ & -1 & 0 & +1 & $+1,41$ \\
$\begin{array}{l}\text { razão entre as } \\
\text { vazões ar/água, } \\
.10^{3}\end{array}$ & $\mathrm{X}_{1}$ & 0,293 & 0,50 & 1,00 & 1,5 & 1,71 \\
razão óleo/água \\
de alimentação, \\
$.10^{4}$
\end{tabular}

A eficiência de separação para cada estágio será calculado de acordo com a Eq.(1).

$$
\eta=\frac{\mathrm{C}_{\mathrm{I}}-\mathrm{C}_{\mathrm{O}}}{\mathrm{C}_{\mathrm{I}}} \cdot 100 \%
$$

Em que $\eta$ é o percentual de eficiência de separação, $C_{I}$ e $C_{O}$ são as concentrações de óleos na entrada e na saída em ppm, respectivamente.

\section{Resultados}

\subsection{Eficiência da Flotação para o Arranjo de Bancada FAD}

As influências das variações dos fatores $X_{1}$ e $X_{2}$ sobre a eficiência da flotação para $o$ primeiro $\left(\mathrm{Y}_{1}\right)$ e o segundo estágio $\left(\mathrm{Y}_{2}\right)$ encontram-se na referida Tabela 2. Em ambos os casos os valores máximos dessas eficiências ocorreram no ponto central do planejamento, denotando uma escolha adequada para os intervalos de valores experimentais adotados. 
Tabela 2 - Matriz de planejamento DCCR e os valores experimentais de fatores observados na eficiência de separação do arranjo de bancada FAD

\begin{tabular}{ccccc}
\hline Experimento & $\mathrm{X}_{1} \cdot 10^{3}(-)$ & $\mathrm{X}_{2} \cdot 10^{4}(-)$ & $\mathrm{Y}_{1}(\%)$ & $\mathrm{Y}_{2}(\%)$ \\
\hline 1 & $0,50(-1)$ & $0,7(-1)$ & 18,00 & 23,00 \\
2 & $0,50(-1)$ & $1,4(+1)$ & 63,00 & 70,00 \\
3 & $1,50(+1)$ & $0,7(-1)$ & 19,00 & 26,00 \\
4 & $1,50(+1)$ & $1,4(+1)$ & 50,00 & 59,00 \\
5 & $0,30(-1.41)$ & $1,05(0.0)$ & 37,00 & 44,00 \\
6 & $1,71(+1.41)$ & $1,05(0.0)$ & 20,00 & 25,00 \\
7 & $1,00(0.0)$ & $0,56(-1.41)$ & 12,00 & 15,00 \\
8 & $1,00(0.0)$ & $1,54(+1.41)$ & 56,00 & 62,00 \\
9 & $1,00(0.0)$ & $1,05(0.0)$ & 62,00 & 75,00 \\
10 & $1,00(0.0)$ & $1,05(0.0)$ & 65,00 & 77,00 \\
11 & $1,00(0.0)$ & $1,05(0.0)$ & 67,00 & 78,00 \\
12 & $1,00(0.0)$ & $1,05(0.0)$ & 61,00 & 74,00 \\
\hline
\end{tabular}

A Figura 2 mostra um gráfico tridimensional da eficiência de separação no primeiro estágio $\left(\mathrm{Y}_{1}\right)$ e a Figura 3 mostra um gráfico tridimensional da eficiência de separação no segundo estágio $\left(\mathrm{Y}_{2}\right)$ do arranjo de bancada $\mathrm{FAD}$, ambos em função dos fatores $\mathrm{X}_{1}$ e $\mathrm{X}_{2}$.

Observa-se que a eficiência de separação passa por condições otimizadas para valores de $\mathrm{X}_{1}$ em torno de $1 \times 10^{3}$ e de $\mathrm{X}_{2}$ em torno de $1 \times 10^{4}$. Observa-se ainda que um segundo estágio em série com o primeiro aumentou consideravelmente a eficiência de remoção de óleo. De acordo com os gráficos a eficiência de remoção com uso dos dois estágios chega a 80\%. Dessa forma, a metodologia proposta permite a recirculação da espuma ou borra oleosa, finalizando o processo com dois fluxos: um para óleo recuperado e outro para água de reuso (água tratada). 


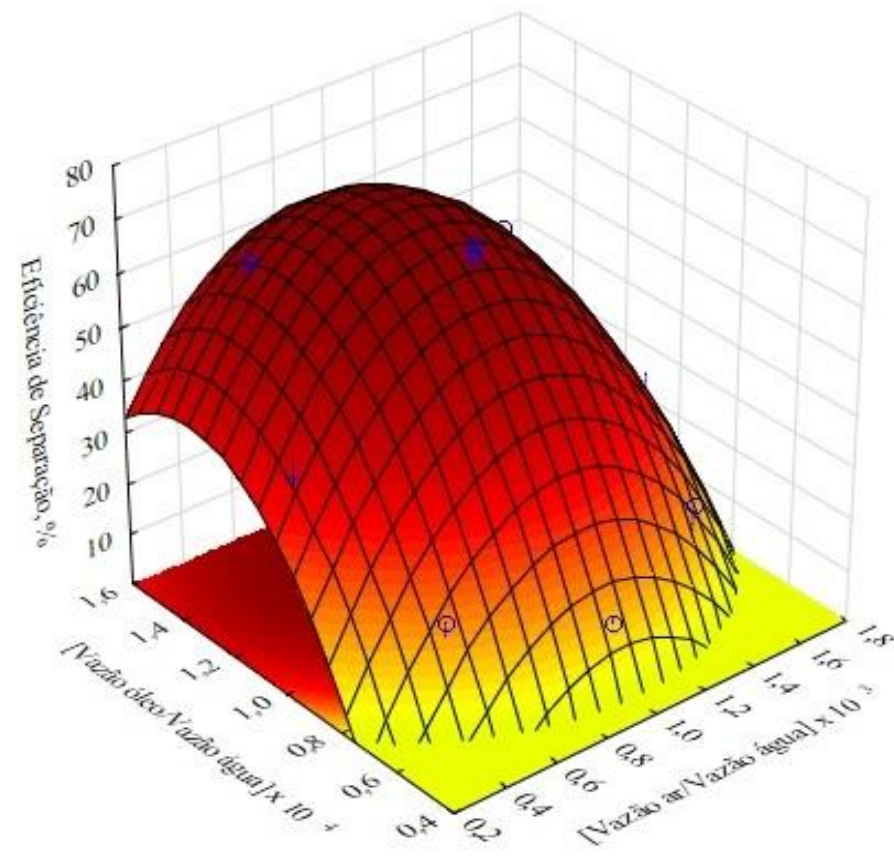

Figura 2 - Eficiência de separação no primeiro estágio do arranjo de bancada FAD

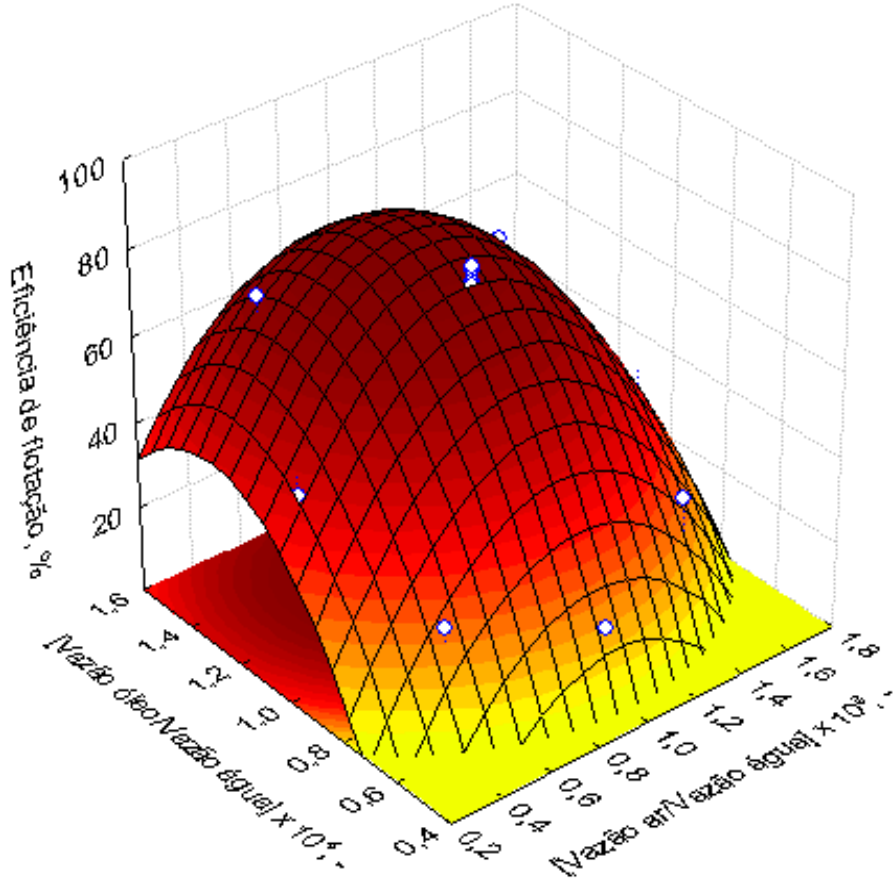

Figura 3 - Eficiência de separação no segundo estágio do arranjo de bancada FAD 


\subsection{Coluna FAD Proposta}

A partir de resultados de melhor eficiência de remoção de óleo utilizando dois estágios do que somente um único estágio para o processo de flotação, foi desenvolvida uma proposta de uma coluna de flotação por ar dissolvido, utilizando múltiplos estágios. Foi proposto um sistema de tratamento, envolvendo separação água-óleo (SAO), envolvendo uma primeira etapa de separação preliminar por decantação contínua e, posteriormente, por meio da técnica de flotação por ar dissolvido (FAD) em coluna. O projeto da coluna FAD do presente trabalho foi desenvolvida tendo por analogia o funcionamento de uma coluna de destilação, conforme Figura 4. O equipamento compreende uma coluna cilíndrica vertical com múltiplos estágios, ou câmaras de flotação dispostas em série. A entrada do efluente no equipamento é realizada pela câmara localizada no topo, produzindo desde esse ponto dois fluxos de materiais com densidades diferentes. A fase aquosa escoa por gravidade para as câmaras inferiores até a base da coluna. Em cada estágio é admitido um fluxo de água saturada por microbolhas, obtido com auxílio da água tratada coletada na base. Um segundo fluxo de material, compreendendo uma espécie de espuma oleosa é obtido por transbordamento em cada câmara.

O número de estágios pode ser selecionado conforme o grau de separação desejado. A água receberá microbolhas de ar em processo de saturação a vácuo, sem utilização de bombas de vácuo ou compressores (Moran et al., 2005), e será levada a passar por um tratamento ao longo do comprimento axial da coluna. A espuma oleosa formada desde o topo da coluna deverá ser retirada de cada estágio pelos topos dos mesmos, permitindo que um eficiente sistema de controle e automação determine o número otimizado desses estágios e a altura da referida coluna, obedecendo a especificações de Resolução do CONAMA 357/2005 (Haarhoff; Edzwald, 2013; Albuquerque et al., 2012; Edzwald; Haarhoff, 2012; Massi et al., 2007; Matsumoto et al., 2005). 


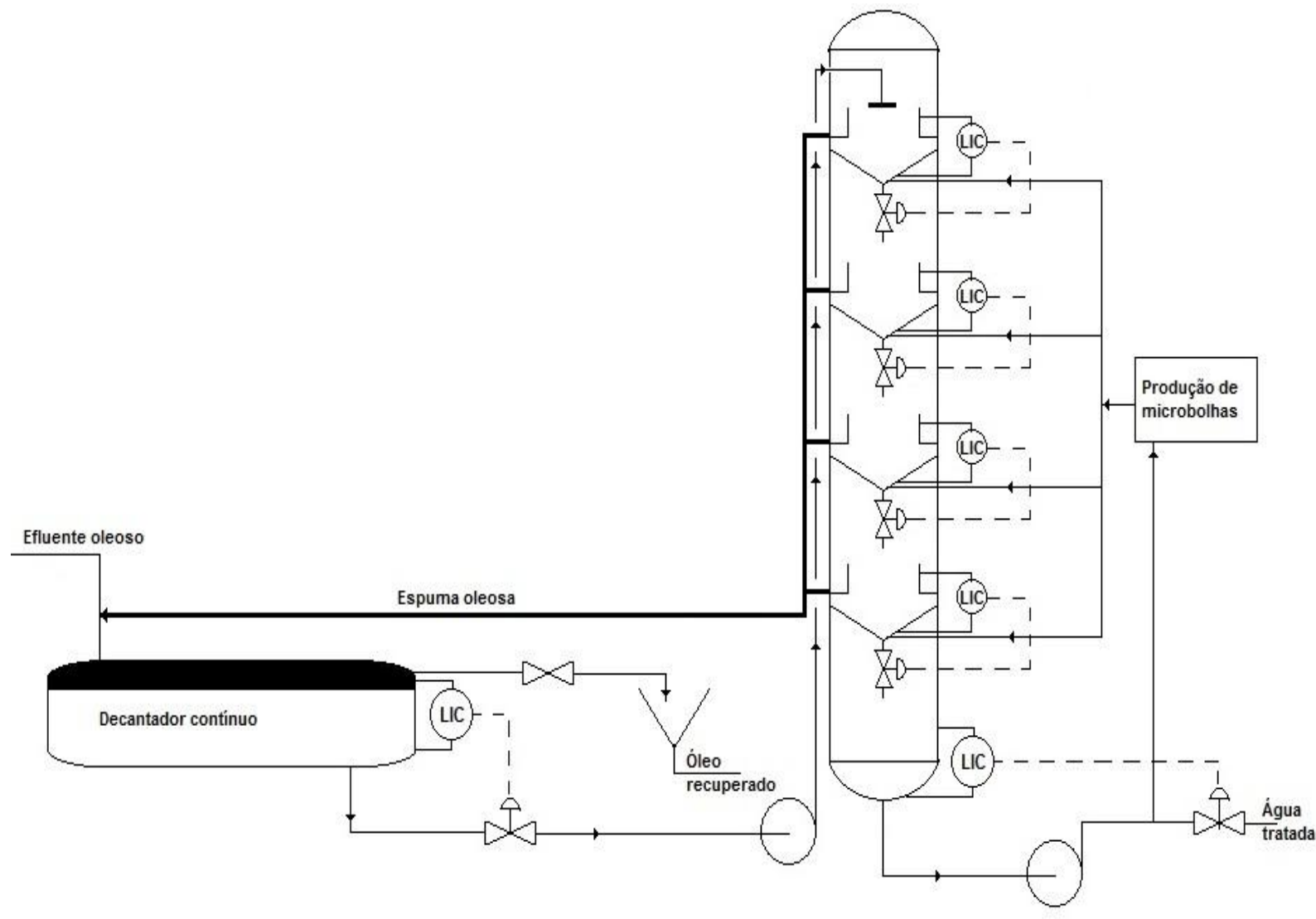

Figura 4 - Esquema dos componentes associados da coluna FAD de estágio proposta por este trabalho

\section{Conclusão}

A utilização de mais de um estágio no processo de flotação aumenta a eficiência de remoção de óleo, comparando com apenas um único estágio. A metodologia proposta mostra-se vantajosa porque é simples e permite a recirculação da espuma ou borra oleosa, finalizando o processo com dois fluxos; um para óleo recuperado e outro para água de reúso. O desenvolvimento de um modelo de simulação para o sistema proposto faz parte das etapas futuras.

\section{Agradecimentos}

Agradecimentos ao Centro de Gestão de Tecnologia e Inovação (CGTI), ao PRH-28 da Agência Nacional do Petróleo e ao Departamento de Engenharia Química da UFPE. 


\section{9 a 22 de outubro de 2014 \\ Florianópolis/SC}

\section{Referências}

ALBUQUERQUE, C. F., LUNA-FINKLER, C. F., RUFINO, D. R., LUNA, J. M., MENEZES, C. T. B., SANTOS, V. A., SARUBBO, L. A. Evaluation of Biosurfactants for Removal of Heavy Metal Ions from Aqueous Effluent Using Flotation Techniques. International Review of Chemical Engineering (Testo Stampato) v.4, p.156-161, 2012.

CONAMA. Conselho Nacional de Meio Ambiente. Brasília, 2005. Resolução $\mathrm{n}^{\circ}$ 357<www.mma.gov.br/port/conama/estr.cfm>. Acesso em: 20 de fevereiro de 2014.

EDZWALD, J.K.; HAARHOFF, J. Dissolved Air Flotation for Water Clarification, McGrawHill, New York and AWWA, Denver, 2012.

FONSECA, L. P. Estudo das variáveis operacionais do processo de separação petróleo-água, utilizando flotação por ar dissolvido. 2010. 56p. Dissertação para obtenção do título de mestre em Engenharia Química. Programa de Pós-Graduação em Engenharia Química. Universidade Federal de Alagoas. 2010.

HAARHOFF, J.; EDZWALD, J. K. Adapting dissolved air flotation for the clarification of seawater. Desalination, v. 311, p. 90-94, 2013.

MASSI, L.; SOUSA, S.R.; LALUCE, C.; JAFELICCI JUNIOR, M. Fundamentos e Aplicação da Flotação como Técnica de Separação de Misturas. p. 1-4, 2007.

MATSUMOTO, T.; SANTANA, S.L.; PERON FILHO, O. Uso de um flotador como prétratamento de Reator Anaeróbio para efluentes de curtume. $23^{\circ}$ Congresso Brasileiro de Engenharia Sanitária e Ambiental. p. 1-4, 2005.

METCALF \& EDDY. Wastewater Engineering: Treatment, Disposal, Reuse. TMH $4^{\circ}$ ed. Boston, Mc Graw Hill, p.1819, 2003.

MONTE, H. M.; ALBUQUERQUE, A. Reutilização de águas residuais. Instituto de Engenharia de Lisboa, 2010.

MORAN, M.J.; SHAPIRO, H.N.; MSON, B.R.; DeWITT, D.P. Introdução à Engenharia de Sistemas Térmicos. Rio de Janeiro: LTC, 2005.

SANTANDER, M.; RODRIGUES, R.T; RUBIO, J. Colloids and Surfaces A: Physicochemical and Engineering Aspects, n. 375 p. 237-244, 2011.

SHUKLA, S.C.; KUNDU, G.; MUKHERJEE, D. Study of gas holdup and pressure characteristics in a column flotation cell using coal. Minerals Engineering, v. 23, p.636 $642,2010$.

VALENTINE, E. G.; CARAWAN R.E. Dissolved Air Flotation Systems (DAFs) for Bakeries. Published by: North Carolina Cooperative Extension Service Publication Number: CD-43. p.13, 1996.

XIAO-BING, L.; JIONG-TIAN, L.; YONG-TIAN, W.; CUN-YING, W.; XIAO-HUA, Z. Separation of Oil from Wastewater by Column Flotation. Journal of China University of Mining \& Technology, v. 17, n.4, p.546 - 551, 2007. 